\title{
A semi-analytical method for calculating rates of new sulfate aerosol formation from the gas phase
}

\author{
J. Kazil ${ }^{1,2}$ and E. R. Lovejoy ${ }^{1}$ \\ ${ }^{1}$ NOAA Earth System Research Laboratory, Boulder, CO, USA \\ ${ }^{2}$ NRC Research Associateship Programs, Washington, D.C., USA \\ Received: 8 January 2007 - Published in Atmos. Chem. Phys. Discuss.: 15 February 2007 \\ Revised: 30 May 2007 - Accepted: 15 June 2007 - Published: 2 July 2007
}

\begin{abstract}
The formation of new aerosol from the gas phase is commonly represented in atmospheric modeling with parameterizations of the steady state nucleation rate. Present parameterizations are based on classical nucleation theory or on nucleation rates calculated with a numerical aerosol model. These parameterizations reproduce aerosol nucleation rates calculated with a numerical aerosol model only imprecisely. Additional errors can arise when the nucleation rate is used as a surrogate for the production rate of particles of a given size. We discuss these errors and present a method which allows a more precise calculation of steady state sulfate aerosol formation rates. The method is based on the semi-analytical solution of an aerosol system in steady state and on parameterized rate coefficients for $\mathrm{H}_{2} \mathrm{SO}_{4}$ uptake and loss by sulfate aerosol particles, calculated from laboratory and theoretical thermodynamic data.
\end{abstract}

\section{Introduction}

Aerosol particles play an important role in the Earth's atmosphere and in the climate system: Aerosols scatter and absorb solar radiation (e.g. Haywood and Boucher, 2000), facilitate heterogeneous and multiphase chemistry (Ravishankara, 1997), and change cloud characteristics in many ways (e.g. Lohmann and Feichter, 2005). Aerosol particles can either be directly emitted from surface sources (primary aerosol) or form from the gas phase (secondary aerosol). The processes and compounds involved in secondary aerosol formation and growth, as well as their relative importance, and the spatial and temporal distribution thereof are the subject of ongoing research. The chemical species of interest include inorganic acids, ammonia, and organic molecules (see, e.g. Heintzenberg, 1989; Heintzenberg et al., 2000; Jacobson

Correspondence to: J. Kazil

(jan.kazil@noaa.gov) et al., 2000; Kulmala et al., 2004a, and references therein). Among these, sulfuric acid stands out due to its very low vapor pressure, its numerous sources, and its ubiquity. In clean areas, such as over oceans, sulfuric acid appears as the driving force of secondary aerosol formation (Clarke, 1992; Brock et al., 1995), while over continents and in particular in the continental boundary layer, recently formed aerosol particles contain in addition to sulfate substantial amounts of ammonia (Smith et al., 2005) or organic matter (Allan et al., 2006; Cavalli et al., 2006), which may be involved in their formation process (Coffman and Hegg, 1995; Kulmala et al., 2004b). Secondary aerosol formation can significantly increase concentrations of aerosol particles and cloud condensation nuclei, and therefore requires dependable representations in atmospheric models (Kulmala et al., 2004a).

\section{Representing secondary aerosol formation in atmo- spheric models}

Detailed representations of secondary aerosol formation, with a molecular size resolution of the involved processes, are numerically expensive and presently used in box (Lehtinen and Kulmala, 2003; Lovejoy et al., 2004) or parcel models (Kazil et al., 2007). In medium- and large scale atmospheric models, numerically less costly parameterizations of the steady state aerosol nucleation rate are used (e.g. Lauer et al., 2005; Ma and von Salzen, 2006). Aerosol nucleation is the process by which supercritical molecular clusters, particles larger than the critical cluster, form from the gas phase. The critical cluster is the smallest particle whose growth due to uptake of gas phase molecules is uninhibited by a thermodynamic barrier.

Different parameterizations of steady state aerosol nucleation rates have been developed: Vehkamäki et al. (2002) and Napari et al. (2002) parameterized nucleation rates calculated using classical nucleation theory, which rests upon

Published by Copernicus Publications on behalf of the European Geosciences Union. 
the determination of the surface tension of small molecular clusters of a given composition, and on the vapor pressures of the involved molecules above the corresponding bulk solution. Modgil et al. (2005) parameterized nucleation rates that were calculated with a numerical aerosol model that resolves the initial steps of cluster formation molecule by molecule.

These parameterizations reproduce aerosol formation rates calculated with numerical aerosol models only imprecisely, for different reasons: On the one hand, the concepts of surface tension and bulk solution break down in the context of small molecular clusters. On the other hand, nucleation rates are highly non-linear and vary by many orders of magnitude over the atmospherically relevant ranges of ambient conditions. A precise parameterization of the nucleation rate may therefore require a large set of basis functions, with a corresponding number of coefficients, that need to be determined from a sufficiently large nucleation rates table. However, generating a large nucleation rates table with a detailed aerosol model may be numerically prohibitive.

Independently of the intrinsic errors of nucleation rate parameterizations, errors can arise when the nucleation rate is used as a surrogate for the production rate of particles of a given size. We have therefore chosen a different approach for calculating secondary aerosol formation rates. The method is based on the semi-analytical solution of an aerosol system in steady state, and on parameterized rate coefficients for the uptake and loss of gas phase molecules by aerosol particles. The thermodynamic parameters (entropy and enthalpy change) for the uptake and loss of gas phase molecules by small molecular clusters, which are needed for the calculation of dependable particle formation rates, have been determined in the laboratory only for few atmospherically relevant systems: Curtius et al. (2001) and Froyd and Lovejoy $(2003 \mathrm{a}, \mathrm{b})$ measured the thermodynamic parameters for the formation of charged sulfuric acid and water clusters, while Hanson and Lovejoy (2006) measured the thermodynamic parameters for their neutral counterparts. We therefore focus in the following on the formation of sulfate aerosol from nucleation of neutral and negative sulfuric acid/water particles. The nucleation of positive sulfuric acid/water particles is thought to be less important for aerosol formation at least at temperatures of the lower troposphere (Froyd and Lovejoy, 2003a), and is not considered here.

\section{Neutral and negative sulfate aerosol formation}

The scheme of neutral and negative $\mathrm{H}_{2} \mathrm{SO}_{4} / \mathrm{H}_{2} \mathrm{O}$ aerosol formation from the gas phase is shown in Fig. 1: The ionization rate $q$ is the rate at which the anions $\mathrm{A}_{0}^{-}$and the cations $\mathrm{A}^{+}$ are produced. Here we assume that $\mathrm{A}_{0}^{-}=\mathrm{NO}_{3}^{-}\left(\mathrm{HNO}_{3}\right)$. The neutral and negative clusters $\mathrm{A}_{i}$ and $\mathrm{A}_{i}^{-}$are defined as

$$
\begin{aligned}
\mathrm{A}_{i} & =\left(\mathrm{H}_{2} \mathrm{SO}_{4}\right)_{i}\left(\mathrm{H}_{2} \mathrm{O}\right)_{\bar{x}(i)} \\
\mathrm{A}_{i}^{-} & =\mathrm{HSO}_{4}^{-}\left(\mathrm{H}_{2} \mathrm{SO}_{4}\right)_{i-1}\left(\mathrm{H}_{2} \mathrm{O}\right)_{\bar{y}(i)}, \quad i=1, \ldots, n .
\end{aligned}
$$

$\bar{x}(i)$ and $\bar{y}(i)$ are the average $\mathrm{H}_{2} \mathrm{O}$ contents of the clusters in equilibrium with respect to $\mathrm{H}_{2} \mathrm{O}$ uptake and loss. $\mathrm{A}_{1}$ is, as a matter of course, gas phase sulfuric acid, which we will denote in the following simply with $\mathrm{H}_{2} \mathrm{SO}_{4}$. The clusters grow and evaporate with the first order rate coefficients

$$
\begin{array}{cc}
\kappa_{i}=k_{a_{i}} \cdot\left[\mathrm{H}_{2} \mathrm{SO}_{4}\right] \quad, \quad \lambda_{i}=k_{d_{i}}, \\
\kappa_{i}^{-}=k_{a_{i}}^{-} \cdot\left[\mathrm{H}_{2} \mathrm{SO}_{4}\right] \quad, \quad \lambda_{i}^{-}=k_{d_{i}}^{-} .
\end{array}
$$

$k_{a_{i}}$ and $k_{d_{i}}$ are the $\mathrm{H}_{2} \mathrm{SO}_{4}$ uptake and evaporation rate coefficients of the $\mathrm{A}_{i}, k_{a_{i}}^{-}$and $k_{d_{i}}^{-}$the $\mathrm{H}_{2} \mathrm{SO}_{4}$ uptake and evaporation rate coefficients of the $\mathrm{A}_{i}^{-}$, averaged over the equilibrium $\mathrm{H}_{2} \mathrm{O}$ distribution of the clusters. The $\omega_{i}$ and $\omega_{i}^{-}$in Fig. 1 are the pseudo first order rate coefficients for loss of the $\mathrm{A}_{i}$ and $\mathrm{A}_{i}^{-}$by coagulation among each other and onto preexisting aerosol. The $p_{i}$ and $p_{i}^{-}$are production rates of the $\mathrm{A}_{i}$ and $\mathrm{A}_{i}^{-}$by coagulation of smaller clusters. The $\alpha_{i}$ are pseudo first order rate coefficients for the recombination of the $\mathrm{A}_{i}^{-}$with the cations $\mathrm{A}^{+}$. The rate coefficients and their calculation are explained in more detail in Sect. 4.

We denote the net steady state formation rate of the $\mathrm{A}_{i}$ and $\mathrm{A}_{i}^{-}$with $i>n$ from the $\mathrm{A}_{i}$ and $\mathrm{A}_{i}^{-}$with $i \leq n$ with $\mathcal{J}\left(n, p, q, r, s, t,\left[\mathrm{H}_{2} \mathrm{SO}_{4}\right]\right) . \mathcal{J}$ is a function of pressure $p$, ionization rate $q$, relative humidity $r, \mathrm{H}_{2} \mathrm{SO}_{4}$ condensational sink $s$, temperature $t$, and of the sulfuric acid gas phase concentration $\left[\mathrm{H}_{2} \mathrm{SO}_{4}\right]$. The pressure dependence of $\mathcal{J}$ is weak if the clusters $\mathrm{A}_{i}$ and $\mathrm{A}_{i}^{-}$with $i \leq n$ are much smaller than the mean free path of gas phase molecules (typically $>100 \mathrm{~nm}$ in atmospheric conditions), when their $\mathrm{H}_{2} \mathrm{SO}_{4}$ uptake and loss as well as their coagulation take place in the free molecular regime. $\mathcal{J}$ can be broken down into three contributions,

$\mathcal{J}\left(n, p, q, r, s, t,\left[\mathrm{H}_{2} \mathrm{SO}_{4}\right]\right)=J_{\text {cond }}+J_{\text {evap }}+J_{\text {coag }}$,

where

$J_{\text {cond }}=k_{a_{n}}\left[\mathrm{H}_{2} \mathrm{SO}_{4}\right]\left[\mathrm{A}_{n}\right]+k_{a_{n}}^{-}\left[\mathrm{H}_{2} \mathrm{SO}_{4}\right]\left[\mathrm{A}_{n}^{-}\right]$

represents for the formation of clusters by condensation of sulfuric acid,

$J_{\text {evap }}=-k_{d_{n+1}}\left[\mathrm{~A}_{n+1}\right]-k_{d_{n+1}}^{-}\left[\mathrm{A}_{n+1}^{-}\right]$

the loss of clusters by evaporation of sulfuric acid, and

$$
\begin{aligned}
J_{\text {coag }} & =\sum_{i=2}^{n} \sum_{j=\max (i, n+1-i)}^{n} k_{c_{i, j}}\left[\mathrm{~A}_{i}\right]\left[\mathrm{A}_{j}\right] \\
& +\sum_{i=2}^{n} \sum_{j=n+1-i}^{n} k_{c_{i, j}}^{-}\left[\mathrm{A}_{i}\right]\left[\mathrm{A}_{j}^{-}\right]
\end{aligned}
$$

the formation of clusters due to coagulation. The calculation of the coagulation rate coefficients $k_{c_{i, j}}$ and $k_{c_{i, j}}^{-}$is explained in Sect. 4.

The smallest neutral cluster whose sulfuric acid content $c$ satisfies

$$
\begin{aligned}
& k_{a_{c}} \cdot\left[\mathrm{H}_{2} \mathrm{SO}_{4}\right] \geq k_{d_{c}} \\
& \wedge \quad k_{a_{i}} \cdot\left[\mathrm{H}_{2} \mathrm{SO}_{4}\right]>k_{d_{i}} \quad \forall i>c
\end{aligned}
$$




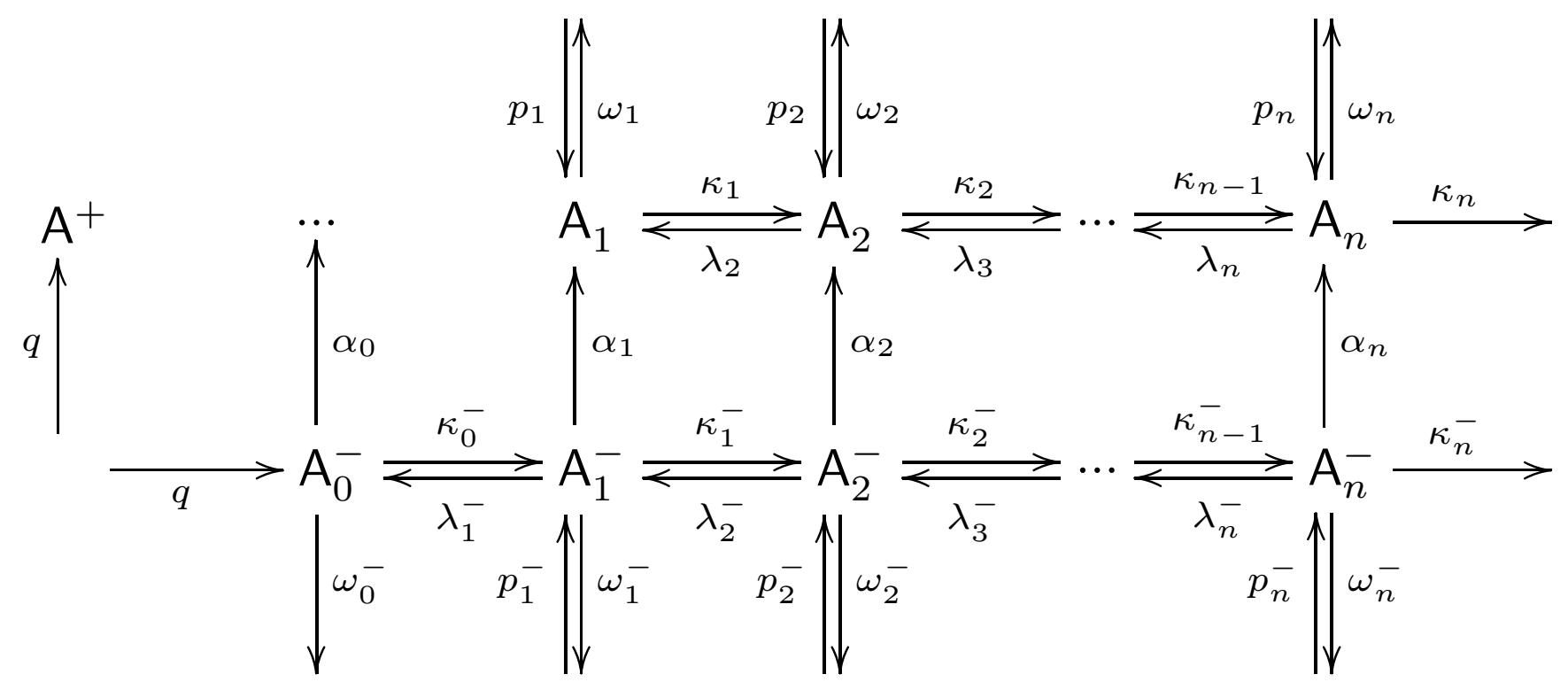

Fig. 1. Reaction scheme of a coupled neutral and negative aerosol system.

is the neutral critical cluster. For $n \gg c$, the particles $\mathrm{A}_{n+1}$ and $\mathrm{A}_{n+1}^{-}$evaporate only very slowly, and $J_{\text {evap }} \approx 0$.

Atmospheric models which account for $\mathrm{H}_{2} \mathrm{SO}_{4} / \mathrm{H}_{2} \mathrm{O}$ particles containing more than $n \mathrm{H}_{2} \mathrm{SO}_{4}$ molecules need to be supplied only with the formation rate

$J\left(n, p, q, r, s, t,\left[\mathrm{H}_{2} \mathrm{SO}_{4}\right]\right)=J_{\text {cond }}+J_{\text {coag }}$

of these particles, since they can either neglect $J_{\text {evap }}$ if $n \gg c$, or otherwise calculate it from the concentrations of the particles they account for. We therefore focus in the following on the particle formation rate $J\left(n, p, q, r, s, t,\left[\mathrm{H}_{2} \mathrm{SO}_{4}\right]\right)$, which we will refer to as nucleation rate for $n=c$.

\section{Rate coefficients}

The rate coefficients for sulfuric acid uptake by the neutral and negative $\mathrm{H}_{2} \mathrm{SO}_{4} / \mathrm{H}_{2} \mathrm{O}$ aerosol particles are calculated with the Fuchs formula for Brownian coagulation (Fuchs, 1964). The effect of particle charge is accounted for as described by Lovejoy et al. (2004). The rate coefficients for sulfuric acid evaporation from the aerosol particles are calculated from the uptake rate coefficients and from the thermodynamic parameters for $\mathrm{H}_{2} \mathrm{SO}_{4}$ uptake/loss by the particles, described in Sect. 5. The resulting $\mathrm{H}_{2} \mathrm{SO}_{4}$ uptake and loss rate coefficients are averaged over the equilibrium probability distributions of the particle $\mathrm{H}_{2} \mathrm{O}$ content, giving the rate coefficients $k_{a_{i}}, k_{d_{i}}, k_{a_{i}}^{-}$, and $k_{d_{i}}^{-}$. The equilibrium probability distributions of the particle $\mathrm{H}_{2} \mathrm{O}$ content and the corresponding averages are calculated from the thermodynamic parameters for $\mathrm{H}_{2} \mathrm{O}$ uptake/loss by the particles, described in Sect. 5.
The rate coefficients $k_{c_{i, j}}$ for coagulation of the neutral particles among each other, the rate coefficients $k_{c_{i, j}}^{-}$for the coagulation of neutral and negative particles, and the rate coefficients $k_{\text {pre, } i}$ and $k_{\text {pre, } i}^{-}$for their coagulation with preexisting aerosol are calculated with the Fuchs formula. The masses and diameters of the particles used in the calculation are determined from their $\mathrm{H}_{2} \mathrm{SO}_{4}$ and average $\mathrm{H}_{2} \mathrm{O}$ contents. The effect of the particle charge is accounted for as described by Lovejoy et al. (2004). Charging of the preexisting aerosol particles is neglected.

The pseudo first order rate coefficients $\omega_{i}$ and $\omega_{i}^{-}$(Fig. 1) for loss of the particles by coagulation with each other and with preexisting aerosol are calculated with

$$
\begin{aligned}
\omega_{i} & =\sum_{j=2}^{n}\left(1+\delta_{i, j}\right) k_{c_{i, j}}\left[\mathrm{~A}_{j}\right] \\
& +\sum_{j=0}^{n} k_{c_{i, j}}^{-}\left[\mathrm{A}_{j}^{-}\right]+\frac{k_{\mathrm{pre}, i}}{k_{\mathrm{pre}, 1}} s \quad, \quad i=1, \ldots, n,
\end{aligned}
$$

and

$\omega_{i}^{-}=\sum_{j=2}^{n} k_{c_{j, i}}^{-}\left[\mathrm{A}_{j}\right]+\frac{k_{\mathrm{pre}, i}^{-}}{k_{\mathrm{pre}, 1}} s \quad, \quad i=0, \ldots, n$,

with the preexisting aerosol $\mathrm{H}_{2} \mathrm{SO}_{4}$ condensational sink $s$. The summation over the neutral cluster concentrations $\left[\mathrm{A}_{j}\right]$ starts with $j=2$, because coagulation with $\mathrm{A}_{1}$ is equivalent to uptake of gas phase $\mathrm{H}_{2} \mathrm{SO}_{4}$, which is accounted for by the $\mathrm{H}_{2} \mathrm{SO}_{4}$ uptake rate coefficients. 
The production rates $p_{i}$ of neutral clusters due to coagulation read

$$
\begin{gathered}
p_{i}=0 \quad, \quad i=1, \ldots, 3, \\
p_{i}=\sum_{j=2}^{i-2} \frac{1+\delta_{j, i-j}}{2} k_{c_{j, i-j}}\left[\mathrm{~A}_{j}\right]\left[\mathrm{A}_{i-j}\right], \\
\quad i=4, \ldots, n .
\end{gathered}
$$

$p_{1}$ equals zero because $\mathrm{A}_{1}$ is gas phase $\mathrm{H}_{2} \mathrm{SO}_{4}$. The $p_{i=2,3}$ equal zero, and the summation giving the $p_{i=4, \ldots, n}$ starts with 2 and ends with $i-2$ because coagulation with $\mathrm{A}_{1}$ is equivalent to uptake of gas phase $\mathrm{H}_{2} \mathrm{SO}_{4}$, which is accounted for by the $\mathrm{H}_{2} \mathrm{SO}_{4}$ uptake rate coefficients.

The production rates $p_{i}^{-}$of negative clusters due to coagulation read

$$
\begin{aligned}
p_{1}^{-} & =0, \\
p_{i}^{-} & =\sum_{j=0}^{i-2} k_{c_{i-j, j}}^{-}\left[\mathrm{A}_{i-j}\right]\left[\mathrm{A}_{j}^{-}\right] \quad, \quad i=2, \ldots, n .
\end{aligned}
$$

$p_{1}^{-}$equals zero and the summation giving the $p_{i=2, \ldots, n}^{-}$ends with $i-2$ because coagulation with $\mathrm{A}_{1}$ is equivalent to uptake of gas phase $\mathrm{H}_{2} \mathrm{SO}_{4}$, which is accounted for by the $\mathrm{H}_{2} \mathrm{SO}_{4}$ uptake rate coefficients.

The pseudo first order rate coefficients $\alpha_{i}=k_{r_{i}}\left[\mathrm{~A}^{+}\right]$describe the recombination of the $\mathrm{A}_{i}^{-}$with cations $\mathrm{A}^{+}$, where the $k_{r_{i}}$ are the rate coefficients for recombination of the anions with the cation population. A mass and size independent recombination rate coefficient $k_{r_{i}} \doteq k_{r}=1.6 \times 10^{-6} \mathrm{~cm}^{3} \mathrm{~s}^{-1}$ (Bates, 1982) is assumed for all anions/cations in this work.

In atmospheric conditions, the mean free path of gas phase molecules is typically $>100 \mathrm{~nm} . \mathrm{H}_{2} \mathrm{SO}_{4}$ uptake and loss as well as the coagulation of particles much smaller than this size take place in the free molecular regime, where the corresponding rate coefficients are essentially independent of pressure. All rate coefficients were therefore calculated at $1013.25 \mathrm{hPa}$.

\section{Thermodynamic parameters for $\mathrm{H}_{2} \mathrm{SO}_{4}$ and $\mathrm{H}_{2} \mathrm{O}$ up- take and loss}

The thermodynamic parameters (entropy and enthalpy change) for uptake and loss of $\mathrm{H}_{2} \mathrm{SO}_{4}$ and $\mathrm{H}_{2} \mathrm{O}$ by the small negative clusters are based on the laboratory measurements of Curtius et al. (2001) and of Froyd and Lovejoy (2003b). The thermodynamic parameters for the formation of $\left(\mathrm{H}_{2} \mathrm{SO}_{4}\right)_{2}\left(\mathrm{H}_{2} \mathrm{O}\right)_{\bar{x}(2)}$ and of $\left(\mathrm{H}_{2} \mathrm{SO}_{4}\right)_{3}\left(\mathrm{H}_{2} \mathrm{O}\right)_{\bar{x}(3)}$ due to uptake of sulfuric acid from the gas phase are calculated explicitly from fits to the laboratory measurements by Hanson and Lovejoy (2006). These fits read, with RH over water in \%,

$$
\begin{aligned}
d S\left(\mathrm{kcal} \mathrm{mol}^{-1} \mathrm{~K}^{-1}\right) & =-0.04 \\
d H\left(\mathrm{kcal} \mathrm{mol}^{-1}\right) & =-18.32-4.55 \times 10^{-3} \cdot \mathrm{RH}
\end{aligned}
$$

for the dimer formation and

$$
\begin{aligned}
d S\left(\mathrm{kcal} \mathrm{mol}^{-1} \mathrm{~K}^{-1}\right) & =-0.045 \\
d H\left(\mathrm{kcal} \mathrm{mol}^{-1}\right) & =-21.41-2.63 \times 10^{-2} \cdot \mathrm{RH}
\end{aligned}
$$

for the trimer formation.

The thermodynamic parameters for large aerosol particles are based on the the liquid drop model and on $\mathrm{H}_{2} \mathrm{SO}_{4}$ and $\mathrm{H}_{2} \mathrm{O}$ vapor pressures over bulk solutions, calculated with a computer code (S. L. Clegg, personal communication, 2007) that uses data from Giauque et al. (1960) and Clegg et al. (1994). It is assumed that charging of large aerosol has a negligible effect on the uptake and loss of gas phase molecules. The thermodynamic parameters for intermediate size particles are a smooth interpolation of the thermodynamic parameters for the small and large particles. For the negative particles, the interpolation scheme by Froyd (2002) is used. In the case of the neutral particles, exponential correction terms as introduced by Lovejoy et al. (2004) are added to the liquid drop model Gibbs free energies. The correction terms used here are adjusted to match the dimer and trimer data in Eqs. (13) and (14): The term $3 \mathrm{e}^{-(m+n) / 5} \mathrm{kcal} / \mathrm{mol}$ is added to the liquid drop Gibbs free energies for the addition of a sulfuric acid molecule to a $\left(\mathrm{H}_{2} \mathrm{SO}_{4}\right)_{m-1}\left(\mathrm{H}_{2} \mathrm{O}\right)_{n}$ cluster and for the addition of a water molecule to a $\left(\mathrm{H}_{2} \mathrm{SO}_{4}\right)_{m}\left(\mathrm{H}_{2} \mathrm{O}\right)_{n-1}$ cluster. The water vapor saturation pressure formulation by Goff (1957) was used in all calculations to transform relative humidity over water to water vapor concentration and vice versa.

\section{Parameterization}

Calculating $\mathrm{H}_{2} \mathrm{SO}_{4}$ uptake and loss rate coefficients as described in Sect. 4 is numerically expensive due to the averaging of the rate coefficients over the cluster water content. Using parameterized rate coefficients and average cluster water contents can reduce the computational burden. We parameterize the rate coefficients $k_{a_{i}}, k_{d_{i}}, k_{a_{i}}^{-}$and $k_{d_{i}}^{-}$for $\mathrm{H}_{2} \mathrm{SO}_{4}$ uptake and loss by the neutral and negative clusters and the average cluster $\mathrm{H}_{2} \mathrm{O}$ contents $\bar{x}(i)$ and $\bar{y}(i)$ as functions of temperature $t$ and relative humidity $r$ with a series of Chebyshev polynomials of the first kind $T_{u}(\bar{t})$ and $T_{v}(\bar{r})$ up to degrees $u^{\prime}$ and $v^{\prime}$, respectively:

$k(t, r) \approx \tilde{k}_{u^{\prime}, v^{\prime}}(t, r)=\sum_{u=0}^{u^{\prime}} \sum_{v=0}^{v^{\prime}} \alpha_{u, v} T_{u}(\bar{t}(t)) T_{v}(\bar{r}(r))$

with $\bar{t}$ and $\bar{r}$ defined as

$$
\begin{gathered}
\bar{t}(t)=\frac{2 t-\left(t_{0}+t_{1}\right)}{t_{1}-t_{0}}, \\
\bar{r}(r)=\frac{2 r-\left(r_{0}+r_{1}\right)}{r_{1}-r_{0}},
\end{gathered}
$$


on the temperature and relative humidity intervals

$$
\begin{gathered}
t \in\left[t_{0}, t_{1}\right], t_{0}=190 \mathrm{~K}, t_{1}=300 \mathrm{~K}, \\
r \in\left[r_{0}, r_{1}\right], r_{0}=0.5 \%, r_{1}=104 \% .
\end{gathered}
$$

We determine the coefficients $\alpha_{u, v}$ for $u, v \leq 20$ using an orthogonality property of the Chebyshev polynomials:

$$
\begin{aligned}
& \alpha_{u, v}=\frac{4}{\pi^{2}\left(1+\delta_{u, 0}\right)\left(1+\delta_{v, 0}\right)} \\
& \int_{-1}^{1} d \bar{t} \int_{-1}^{1} d \bar{r} k(\bar{t}, \bar{r}) \frac{T_{u}(\bar{t}) T_{v}(\bar{r})}{\sqrt{1-(\bar{t})^{2}} \sqrt{1-(\bar{r})^{2}}} .
\end{aligned}
$$

We then measure the error of the approximation (15) with

$E_{u^{\prime}, v^{\prime}}=\max \left|\frac{\tilde{k}_{u^{\prime}, v^{\prime}}(t, r)-k(t, r)}{k(t, r)}\right|$

and determine the cutoff orders $u^{\prime} \leq 20$ and $v^{\prime} \leq 20$ which minimize $E_{u^{\prime}, v^{\prime}}$.

\section{Semi-analytical solution for aerosol schemes in steady state}

\subsection{Neutral aerosol}

Here we give a semi-analytical solution for the steady state concentrations of the particles $\mathrm{A}_{i=2, \ldots, n}$ in the aerosol scheme in Fig. 2, at a given concentration of the gas phase molecule $A_{1}$. The particles are produced by sources at the rates $q_{i}$ and lost in sinks with the pseudo first order rate coefficients $\rho_{i}$. They grow by condensation of the gas phase molecules $\mathrm{A}_{1}$ with the pseudo first order rate coefficients $\kappa_{i}$ and decay by evaporation of those molecules with the pseudo first order rate coefficients $\lambda_{i}$. Let us start by assuming that the aerosol particles do not interact with each other (no coagulation). With the total pseudo first order rate coefficient for loss of the $\mathrm{A}_{i}$

$\sigma_{i} \doteq \kappa_{i}+\lambda_{i}+\rho_{i} \quad, \quad i=2, \ldots, n$

the system of differential equations for the concentrations $\left[\mathrm{A}_{i}\right]$ reads

$$
\begin{aligned}
\frac{d\left[\mathrm{~A}_{i}\right]}{d t}= & q_{i}-\sigma_{i}\left[\mathrm{~A}_{i}\right]+\kappa_{i-1}\left[\mathrm{~A}_{i-1}\right]+\lambda_{i+1}\left[\mathrm{~A}_{i+1}\right], \\
& i=2, \ldots, n-1, \\
\frac{d\left[\mathrm{~A}_{n}\right]}{d t}= & q_{n}-\sigma_{n}\left[\mathrm{~A}_{n}\right]+\kappa_{n-1}\left[\mathrm{~A}_{n-1}\right] .
\end{aligned}
$$

The $\left[\mathrm{A}_{i}\right]$ in steady state $\left(d\left[\mathrm{~A}_{i}\right] / d t=0\right)$ can be calculated from this system of equations with

$$
\left[\mathrm{A}_{i}\right]=R_{i-1}\left[\mathrm{~A}_{i-1}\right]+S_{i-1} \quad, \quad i=2, \ldots, n \quad .
$$

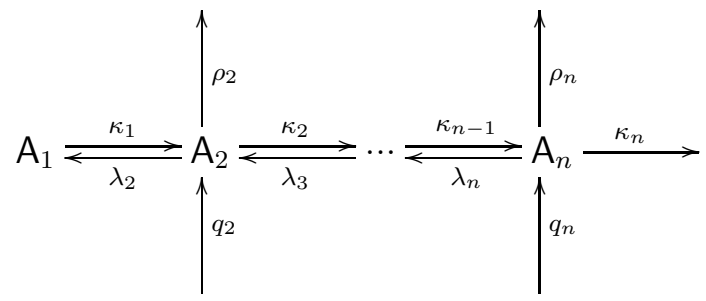

Fig. 2. Reaction scheme of a neutral aerosol system.

The coefficients $R_{i}$ and $S_{i}$ read

$$
\begin{aligned}
& R_{n-1}=\frac{\kappa_{n-1}}{\sigma_{n}}, \\
& R_{i}=\frac{\kappa_{i}}{\sigma_{i+1}-\lambda_{i+2} R_{i+1}}, \quad i=n-2, \ldots, 1, \\
& S_{n-1}=\frac{q_{n}}{\sigma_{n}}, \\
& S_{i}=\frac{q_{i+1}+\lambda_{i+2} S_{i+1}}{\sigma_{i+1}-\lambda_{i+2} R_{i+1}} \quad, \quad i=n-2, \ldots, 1 .
\end{aligned}
$$

Loss of the particles by self-coagulation can be accounted for by substituting the $\sigma_{i}$ according to

$\sigma_{i} \rightarrow \sigma_{i}+\sum_{j=2}^{n}\left(1+\delta_{i, j}\right) k_{c_{i, j}}\left[\mathrm{~A}_{j}\right] \quad, \quad i=2, \ldots, n$

Production of the particles due to self-coagulation can be accounted for by substituting the $q_{i}$ according to

$$
\begin{gathered}
q_{i} \rightarrow q_{i}+\sum_{j=2}^{i-2} \frac{1+\delta_{j, i-j}}{2} k_{c_{j, i-j}}\left[\mathrm{~A}_{j}\right]\left[\mathrm{A}_{i-j}\right], \\
i=4, \ldots, n .
\end{gathered}
$$

$k_{c_{i, j}}$ is the rate coefficient for the coagulation of two particles $\mathrm{A}_{i}$ and $\mathrm{A}_{j}$, which upon coagulation produce a particle $\mathrm{A}_{i+j}$. The $\left[\mathrm{A}_{i}\right]$ in steady state can then be obtained by iterating the solution (22) and (23), starting e.g. with $\left[\mathrm{A}_{i}\right]=0$ for $i=2, \ldots, n$ and updating the cluster concentrations after each iteration. The $\left[\mathrm{A}_{i}\right]$ after the first iteration will be identical with the $\left[\mathrm{A}_{i}\right]$ without coagulation.

\subsection{Negative aerosol}

A semi-analytical solution for the steady state concentrations of the particles $\mathrm{A}_{i=0, \ldots, n}^{-}$in the aerosol scheme in Fig. 3 is given here. The particles are produced by sources at the rates $q_{i}^{-}$and lost in sinks with the pseudo first order rate coefficients $\rho_{i}^{-}$. They grow by condensation of the gas phase molecules $\mathrm{A}_{1}$ with the pseudo first order rate coefficients $\kappa_{i}^{-}$ and decay by evaporation of those molecules with the pseudo first order rate coefficients $\lambda_{i}^{-}$. Due to their mutual electrostatic repulsion it is safe to assume that the particles do not 


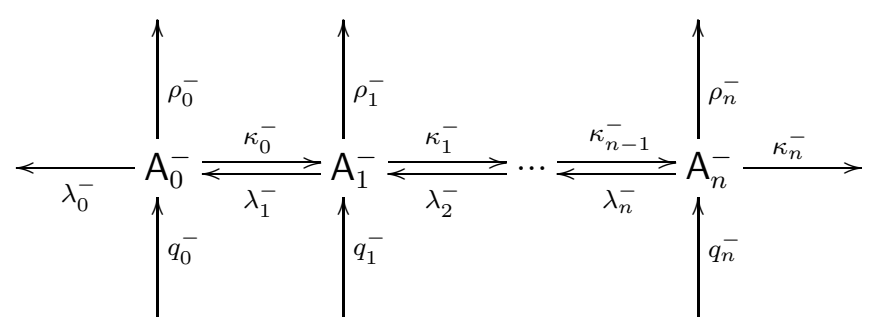

Fig. 3. Reaction scheme of a negative aerosol system.

coagulate. With the total pseudo first order rate coefficient for loss of the $\mathrm{A}_{i}^{-}$

$\sigma_{i}^{-} \doteq \kappa_{i}^{-}+\lambda_{i}^{-}+\rho_{i}^{-} \quad, \quad i=0, \ldots, n$

the system of differential equations for the concentrations $\left[\mathrm{A}_{i}^{-}\right]$reads

$$
\begin{aligned}
\frac{d\left[\mathrm{~A}_{0}^{-}\right]}{d t}= & q_{0}^{-}-\sigma_{0}^{-}\left[\mathrm{A}_{0}^{-}\right]+\lambda_{1}^{-}\left[\mathrm{A}_{1}^{-}\right], \\
\frac{d\left[\mathrm{~A}_{i}^{-}\right]}{d t}= & q_{i}^{-}-\sigma_{i}^{-}\left[\mathrm{A}_{i}^{-}\right]+\kappa_{i-1}^{-}\left[\mathrm{A}_{i-1}^{-}\right] \lambda_{i+1}^{-}\left[\mathrm{A}_{i+1}^{-}\right], \\
& i=1, \ldots, n-1, \\
\frac{d\left[\mathrm{~A}_{n}^{-}\right]}{d t}= & q_{n}^{-}-\sigma_{n}^{-}\left[\mathrm{A}_{n}^{-}\right]+\kappa_{n-1}^{-}\left[\mathrm{A}_{n-1}^{-}\right] .
\end{aligned}
$$

The $\left[\mathrm{A}_{i}^{-}\right]$in steady state $\left(d\left[\mathrm{~A}_{i}^{-}\right] / d t=0\right)$ can be calculated from this system of equations with

$$
\begin{aligned}
{\left[\mathrm{A}_{0}^{-}\right] } & =\frac{q_{0}^{-}+\lambda_{1}^{-} S_{0}^{-}}{\sigma_{0}^{-}-\lambda_{1}^{-} R_{0}^{-}}, \\
{\left[\mathrm{A}_{i}^{-}\right] } & =R_{i-1}^{-}\left[\mathrm{A}_{i-1}^{-}\right]+S_{i-1}^{-} \quad, \quad i=1, \ldots, n .
\end{aligned}
$$

The coefficients $R_{i}^{-}$and $S_{i}^{-}$read

$$
\begin{aligned}
& R_{n-1}^{-}=\frac{\kappa_{n-1}^{-}}{\sigma_{n}^{-}}, \\
& R_{i}^{-}=\frac{\kappa_{i}^{-}}{\sigma_{i+1}^{-}-\lambda_{i+2}^{-} R_{i+1}^{-}} \quad, \quad i=n-2, \ldots, 0, \\
& S_{n-1}^{-}=\frac{q_{n}^{-}}{\sigma_{n}^{-}}, \\
& S_{i}^{-}=\frac{q_{i+1}^{-}+\lambda_{i+2}^{-} S_{i+1}^{-}}{\sigma_{i+1}^{-}-\lambda_{i+2}^{-} R_{i+1}^{-}} \quad, \quad i=n-2, \ldots, 0 .
\end{aligned}
$$

Loss of the particles by recombination with cations can be accounted for in the system of differential equations (27) by substituting the $\sigma_{i}^{-}$according to

$\sigma_{i}^{-} \rightarrow \sigma_{i}^{-}+k_{r_{i}} \sum_{j=0}^{n}\left[\mathrm{~A}_{j}^{-}\right] \quad, \quad i=0, \ldots, n$ where $\sum_{j=0}^{n}\left[\mathrm{~A}_{j}^{-}\right]$is the cation concentration in charge equilibrium, and the $k_{r_{i}}$ the rate coefficients for the recombination of the $\mathrm{A}_{i}^{-}$with the cation population. The $\left[\mathrm{A}_{i}^{-}\right]$in steady state can then be obtained by iterating the solution (28) and (29), starting e.g. with $\left[\mathrm{A}_{i}^{-}\right]=0 \forall i$ and updating the cluster concentrations after each iteration. The $\left[\mathrm{A}_{i}^{-}\right]$after the first iteration will be identical with the $\left[\mathrm{A}_{i}^{-}\right]$without recombination.

\subsection{Coupled neutral and negative aerosol}

The semi-analytical approach can be used to solve the coupled neutral/negative aerosol scheme in Fig. 1 in steady state at a fixed gas phase concentration of sulfuric acid $\left[\mathrm{A}_{1}\right]=\left[\mathrm{H}_{2} \mathrm{SO}_{4}\right]$. The solutions for the neutral and negative aerosol schemes are not iterated independently, but alternatingly: The first iteration of the negative solution is applied to the bottom portion of the scheme, giving the concentrations of the negative clusters $\left[\mathrm{A}_{i}^{-}\right]$. With these the production and loss rates of the neutral clusters $\mathrm{A}_{i}$ are calculated, and the first iteration of the neutral solution applied to the top part of the scheme, giving the concentrations $\left[\mathrm{A}_{i}\right]$. These are then used to calculate the production and loss rates of the $\mathrm{A}_{i}^{-}$, and the next iteration of the negative solution is applied to the bottom of the scheme. Iterating the procedure until a satisfactory degree of convergence is attained yields the cluster concentrations $\left[\mathrm{A}_{i}\right]$ and $\left[\mathrm{A}_{i}^{-}\right]$in steady state. The neutral and negative cluster concentrations can then be used to calculate $J\left(n, p, q, r, s, t,\left[\mathrm{H}_{2} \mathrm{SO}_{4}\right]\right)$ from Eqs. (4), (6), and (8).

\section{Numerical aerosol model}

We use a numerical aerosol model to calculate reference particle formation rates. The model integrates the system of differential equations for the concentrations of the neutral and negative aerosol particles $\mathrm{A}_{i=2, \ldots, n}$ and $\mathrm{A}_{i=0, \ldots, n}^{-}$in Fig. 1 for a given set of constant parameters (pressure $p$, ionization rate $q$, temperature $t$, relative humidity $r$, preexisting aerosol $\mathrm{H}_{2} \mathrm{SO}_{4}$ condensational sink $s$, and gas phase sulfuric acid concentration $\left[\mathrm{H}_{2} \mathrm{SO}_{4}\right]=\left[\mathrm{A}_{1}\right]$ ) until the time derivative of the aerosol concentrations falls below a given threshold. The aerosol concentrations and the formation rate $J\left(n, p, q, r, s, t,\left[\mathrm{H}_{2} \mathrm{SO}_{4}\right]\right)$ are then assumed to be good approximations of their steady state values. Alternatively, the model can be run for a given period of time, e.g. $1200 \mathrm{~s}$, a common time step in large scale atmospheric modeling.

\section{Comparison of different particle formation rates}

In this section we compare steady state particle formation rates $J\left(n, p, q, r, s, t,\left[\mathrm{H}_{2} \mathrm{SO}_{4}\right]\right)$ calculated with different methods and using varied assumptions, given in Table 1. The comparisons are performed for particle formation rates exceeding $10^{-6} \mathrm{~cm}^{-3} \mathrm{~s}^{-1}$, as smaller formation 
Table 1. Details of the steady state particle formation rate calculations.

\begin{tabular}{|c|c|c|c|c|c|c|c|c|}
\hline Particle formation rate & $J_{1}$ & $J_{2}$ & $J_{3}$ & $J_{4}$ & $J_{5}$ & $J_{6}$ & $J_{7}$ & $J_{8}$ \\
\hline Solution & $\begin{array}{l}\text { numerical } \\
\text { integration }\end{array}$ & $\begin{array}{l}\text { numerical } \\
\text { integration }\end{array}$ & $\begin{array}{l}\text { numerical } \\
\text { integration }\end{array}$ & $\begin{array}{l}\text { numerical } \\
\text { integration }\end{array}$ & $\begin{array}{l}\text { numerical } \\
\text { integration }\end{array}$ & $\begin{array}{l}\text { numerical } \\
\text { integration }\end{array}$ & $\begin{array}{c}\text { semi- } \\
\text { analytical }\end{array}$ & $\begin{array}{c}\text { semi- } \\
\text { analytical }\end{array}$ \\
\hline $\begin{array}{l}\text { Size of particles } \\
\text { formed }\end{array}$ & $\begin{array}{l}\text { super- } \\
\text { critical }\end{array}$ & $>2.5 \mathrm{~nm}$ & $\begin{array}{l}\text { super- } \\
\text { critical }\end{array}$ & $>2.5 \mathrm{~nm}$ & $\begin{array}{l}\text { super- } \\
\text { critical }\end{array}$ & $>2.5 \mathrm{~nm}$ & $\begin{array}{l}\text { super- } \\
\text { critical }\end{array}$ & $>2.5 \mathrm{~nm}$ \\
\hline Self-coagulation & on & on & off & off & on & on & on & on \\
\hline $\begin{array}{l}\text { Coagulation with } \\
\text { preexisting aerosol }\end{array}$ & on & on & on & on & on & on & on & on \\
\hline $\begin{array}{l}\mathrm{H}_{2} \mathrm{SO}_{4} \text { uptake/loss } \\
\text { rate coefficients } \\
\text { parameterized }\end{array}$ & no & no & no & no & yes & yes & yes & yes \\
\hline
\end{tabular}

rates can in general be neglected in the context of atmospheric aerosol formation. The particle formation rates are sampled on a grid of parameters covering the intervals $[2,35] \mathrm{cm}^{-3} \mathrm{~s}^{-1}$ (ionization rate $q$ ), $[25,104] \%$ (relative humidity $r$ ), $[0,0.01] \mathrm{s}^{-1}$ (preexisting aerosol $\mathrm{H}_{2} \mathrm{SO}_{4}$ condensational sink $s$ ), $[190,285] \mathrm{K}$ (temperature $t$ ), and $\left[10^{6}, 2 \times 10^{8}\right] \mathrm{cm}^{-3}$ (sulfuric acid gas phase concentration $\left[\mathrm{H}_{2} \mathrm{SO}_{4}\right]$ ), with 7 equidistant grid points on each interval. While this parameter grid covers typical tropospheric conditions, the resulting samples will produce an incomplete picture of the differences between the particle formation rates: The extent and resolution of the grid introduce a sampling uncertainty. Moreover, the deviations between the particle formation rates are not a representative measure of their performance when used in an atmospheric model, as the joint probability distribution of the parameters controlling aerosol formation needs not to be uniform in the atmosphere.

Relative humidities below $25 \%$, sulfuric acid concentrations below $10^{6} \mathrm{~cm}^{-3}$, and temperatures above $285 \mathrm{~K}$ were excluded from the comparison: The numerical model described in Sect. 8 is unable reach the steady state criterion for unfavorable combinations of these parameters, when the particle formation rates are extremely small $\left(\ll 10^{-6} \mathrm{~cm}^{-3} \mathrm{~s}^{-1}\right)$, possibly due to numerical errors. The pressure $p$ is set to $1013.25 \mathrm{hPa}$ in all calculations, as the considered particles are much smaller than the mean free path of gas phase molecules, and their processes take place in the free molecular regime, with a negligible pressure dependence.

9.1 Nucleation rate as a surrogate for the formation rate of particles of a given size

In large scale atmospheric models treating sulfate aerosol, particle formation rates are usually calculated with nucleation rate parameterizations. The smallest represented par- ticles in these models (e.g. Lauer et al., 2005; Ma and von Salzen, 2006) may be larger $(2-10 \mathrm{~nm})$ than the neutral critical cluster, which contains only a few sulfuric acid molecules in conditions favorable for nucleation. The loss of supercritical particles smaller than the smallest represented particles due to coagulation among each other and with larger aerosol is then neglected, leading to an overestimation of particle formation rates. The resulting errors add to the intrinsic errors of aerosol nucleation parameterizations, which may exceed a factor of 2 (Vehkamäki et al., 2002; Modgil et al., 2005).

Figure 4a compares nucleation rates with formation rates of particles exceeding $2.5 \mathrm{~nm}$ in diameter, and illustrates the errors which may arise when the aerosol nucleation rate is used in lieu of the formation rate of larger particles: The nucleation rates markedly overestimate the $>2.5 \mathrm{~nm}$ particle formation rates, in some cases by many orders of magnitude.

A modified approach of calculating the formation rates of particles exceeding a given diameter $D$ is the scaling of the nucleation rates with the factor $\left(d^{\prime} / D^{\prime}\right)^{3}$, where $d^{\prime}$ is the diameter of the smallest supercritical particle in given conditions, and $D^{\prime}$ the diameter of the smallest particle exceeding the diameter $D$. This is equivalent to the assumption that the particles exceeding the diameter $D$ form solely by coagulation, which entails conservation of the total volume of the particles. In reality, growth by condensation of vapor molecules contributes significantly to the formation of larger particles, and the scaled nucleation rates will tend to underestimate the formation rates of particles exceeding a given diameter. This is illustrated in Fig. $4 \mathrm{~b}$, which compares nucleation rates scaled with $\left(d^{\prime} / D^{\prime}\right)^{3}$ with the formation rates of particles exceeding $2.5 \mathrm{~nm}$ in diameter: The majority of the scaled nucleation rates underestimate the $>2.5 \mathrm{~nm}$ particle formation rates by up to one order of magnitude, while overestimation occurs in some cases by many orders of magnitude. 

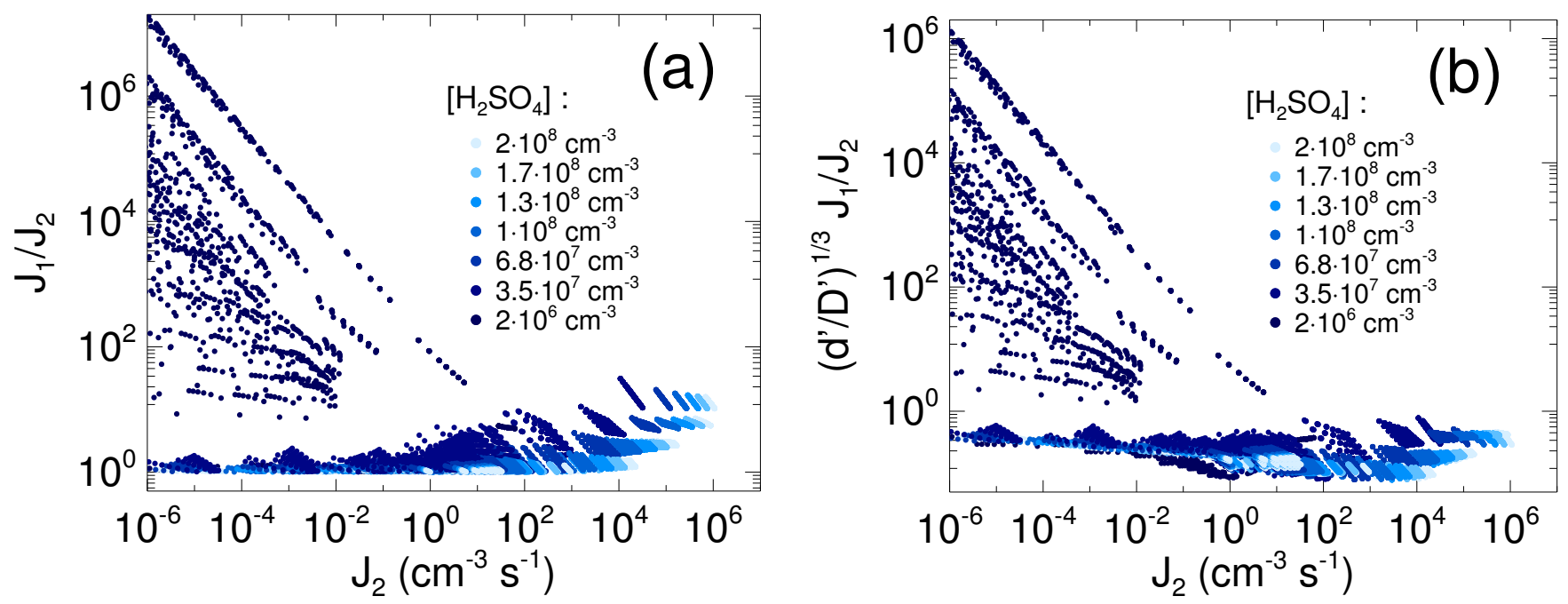

Fig. 4. (a) Comparison of the nucleation rate $J_{1}$ with the formation rate $J_{2}$ of particles exceeding $2.5 \mathrm{~nm}$ in diameter. (b) Comparison of the nucleation rate $J_{1}$, scaled with the factor $\left(d^{\prime} / D^{\prime}\right)^{3}$, with the formation rate $J_{2}$ of particles exceeding $2.5 \mathrm{~nm}$ in diameter. $d^{\prime}$ is the diameter of the smallest supercritical particle in given conditions, $D^{\prime}$ the diameter of the smallest particle exceeding $2.5 \mathrm{~nm}$. The particle formation rate calculations are described in more detail in Table 1 .

In both cases (Figs. 4a and b) the largest differences between the nucleation rate and the $>2.5 \mathrm{~nm}$ particle formation rate occur at the lowest $\mathrm{H}_{2} \mathrm{SO}_{4}$ concentrations and at the lowest temperatures (not shown). This can be explained as follows: At very low temperatures the neutral critical cluster contains very few $\mathrm{H}_{2} \mathrm{SO}_{4}$ molecules, and even comparably low $\mathrm{H}_{2} \mathrm{SO}_{4}$ concentrations can sustain non-negligible nucleation rates. However, at low $\mathrm{H}_{2} \mathrm{SO}_{4}$ concentrations, particles grow slowly, and a given nucleation rate may result in a much smaller formation rate of $>2.5 \mathrm{~nm}$ particles, owing to loss of particles due to coagulation among each other and with preexisting aerosol.

\subsection{Self-coagulation and particle formation}

Kerminen and Kulmala (2002) have developed an analytical method to calculate the formation rate of particles of a given size from the formation rate of particles of a smaller size. The method accounts for coagulation with preexisting aerosol, but neglects self-coagulation. Self-coagulation is the coagulation of the forming particles among each other, as opposed to coagulation with preexisting, typically larger aerosol particles. Unlike coagulation with preexisting aerosol, selfcoagulation acts not only as a particle sink, but also contributes to the formation of new particles.

Figure 5a compares the nucleation rate calculated with and without self-coagulation of the nucleating particles. 99\% of the nucleation rates calculated without self-coagulation lie within $29 \%$ of the nucleation rates calculated with selfcoagulation. Figure $5 b$ shows the errors encountered when calculating the formation rate of particles exceeding $2.5 \mathrm{~nm}$ in diameter without self-coagulation: Here, $31 \%$ of the parti- cle formation rates calculated without self-coagulation deviate $99 \%$ or more from the particle formation rates calculated with self-coagulation. In both cases the largest deviations occur at the low end of the considered temperature range ( $\leq 206 \mathrm{~K}$ for the nucleation and $\leq 238 \mathrm{~K}$ for the $>2.5 \mathrm{~nm}$ particle formation rate). Hence neglecting self-coagulation is a reasonable approximation in the calculation of the steady state formation rate for small particles or at sufficiently high temperatures.

\subsection{Semi-analytical versus numerical particle formation} rate calculation

Here we compare the particle formation rates calculated with the semi-analytical method (described in Sect. 7) with particle formation rates calculated with the numerical aerosol model (described in Sect. 8). Both methods employ parameterized $\mathrm{H}_{2} \mathrm{SO}_{4}$ uptake and loss rate coefficients and average particle $\mathrm{H}_{2} \mathrm{O}$ contents (Sect. 6). The rate coefficients for coagulation of the particles among each other and with preexisting aerosol are calculated as described in Sect. 4.

Figure 6a shows the relative deviations of the semianalytical nucleation rates with respect to the numerical nucleation rates. The deviations are minuscule: The maximum error amounts to $0.41 \%$. Figure $6 \mathrm{~b}$ shows the relative deviation of the semi-analytical formation rates of particles exceeding $2.5 \mathrm{~nm}$ in diameter with respect to the corresponding numerical particle formation rates. These deviations are small: The maximum error amounts to $2.0 \%$.

The semi-analytical method is faster than the numerical model when run for a time period of $1200 \mathrm{~s}$ instead into steady state roughly by a factor of 50 in the case of the 

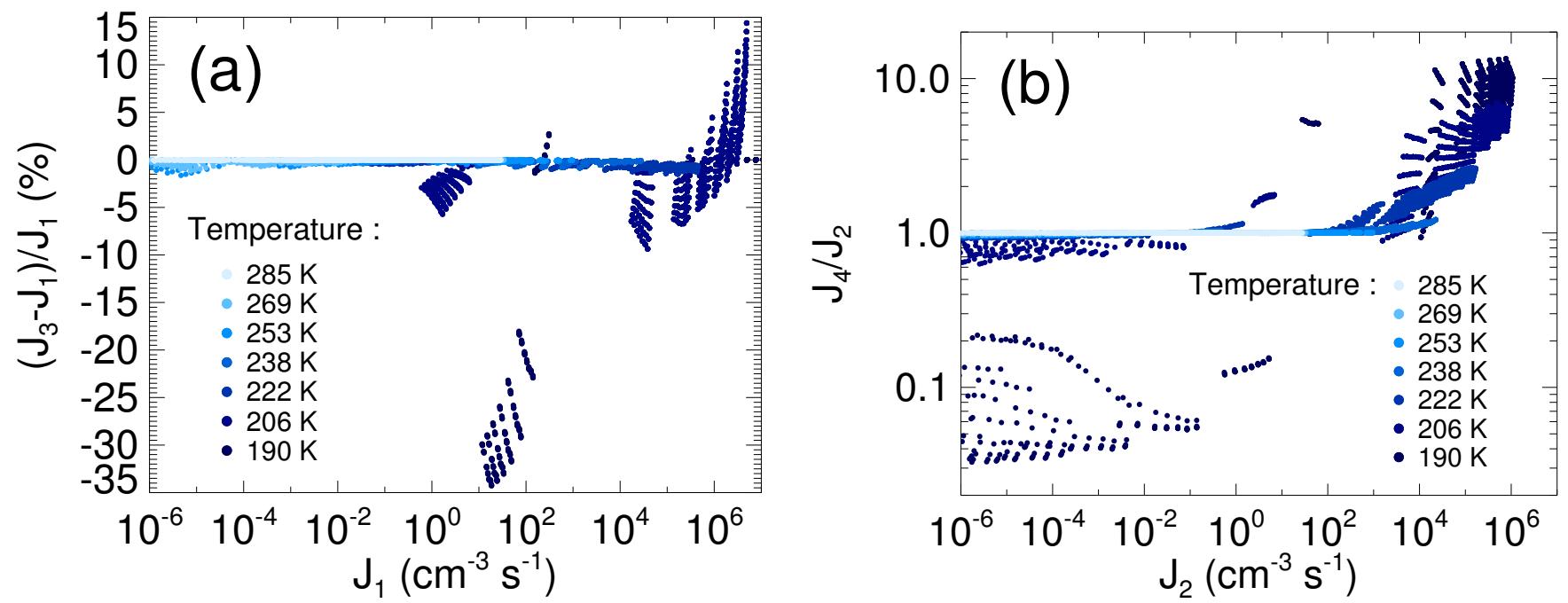

Fig. 5. (a) Comparison of the nucleation rate $J_{3}$, calculated with self-coagulation of the nucleating particles switched off, with the nucleation rate $J_{1}$, calculated with self-coagulation acting both as a particle sink as well as a contribution to the nucleation rate. (b) Comparison of the formation rate $J_{4}$ of particles exceeding $2.5 \mathrm{~nm}$ in diameter, calculated with self-coagulation switched off, with the formation rate $J_{2}$ of particles exceeding $2.5 \mathrm{~nm}$ in diameter, calculated with self-coagulation acting both as a particle sink as well as a contribution to the particle formation rate. The particle formation rate calculations are described in more detail in Table 1 .
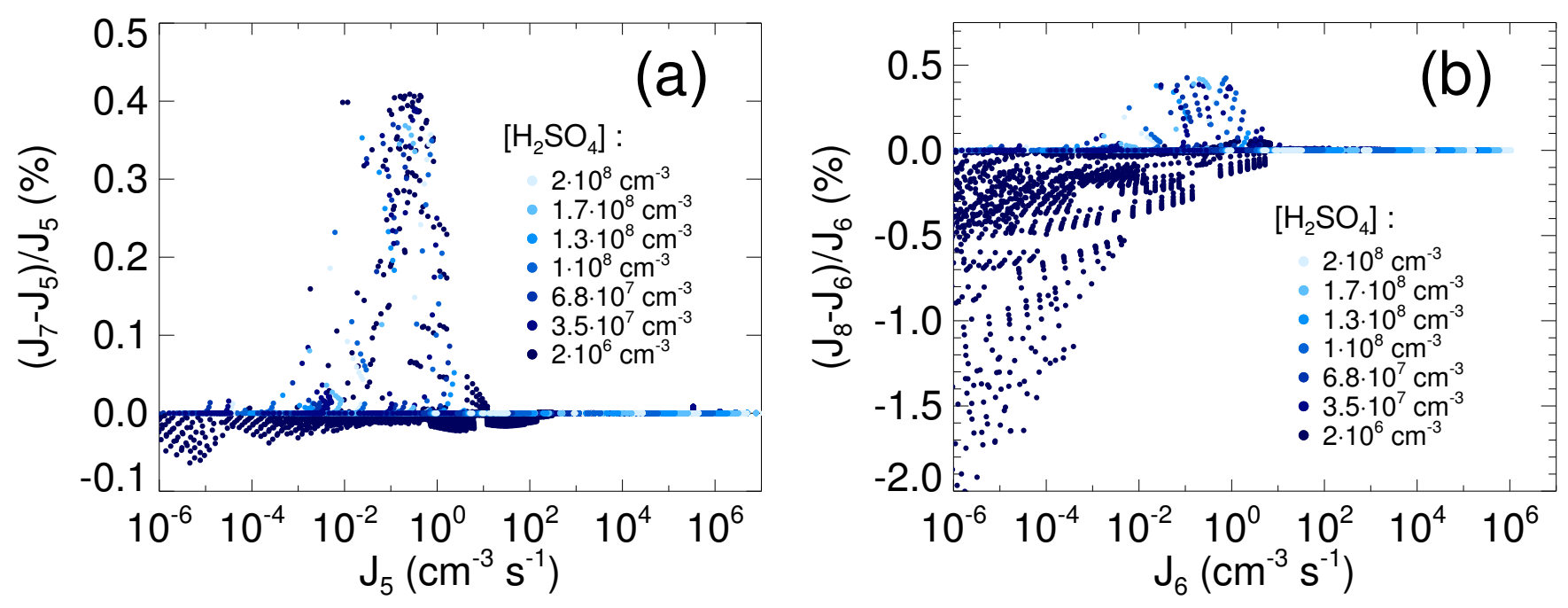

Fig. 6. (a) Comparison of the nucleation rate $J_{7}$, calculated with our semi-analytical method, with the nucleation rate $J_{5}$ calculated with a numerical aerosol model. (b) Comparison of the formation rate $J_{8}$ of aerosol particles exceeding $2.5 \mathrm{~nm}$ in diameter, calculated with our semi-analytical method, with the particle formation rate $J_{6}$ of particles exceeding $2.5 \mathrm{~nm}$ in diameter, calculated with a numerical aerosol model. Here, both the semi-analytical method and the numerical model use parameterized rate coefficients for the uptake and loss of $\mathrm{H}_{2} \mathrm{SO}_{4}$ by the aerosol particles, as well as parameterized average particle $\mathrm{H}_{2} \mathrm{O}$ contents. The particle formation rate calculations are described in more detail in Table 1.

$>2.5 \mathrm{~nm}$ particle formation rates. A further acceleration can be achieved when requirements on precision are relaxed, e.g. by reducing the number of iterations in the semi-analytical method. The time for calculating the rate coefficients has been excluded from this comparison.
9.4 Semi-analytical particle formation rates using parameterized rate coefficients versus numerical particle formation rates using calculated rate coefficients

Here we compare particle formation rates calculated with the semi-analytical method of Sect. 7, using parameterized $\mathrm{H}_{2} \mathrm{SO}_{4}$ uptake and loss rate coefficients and average particle 

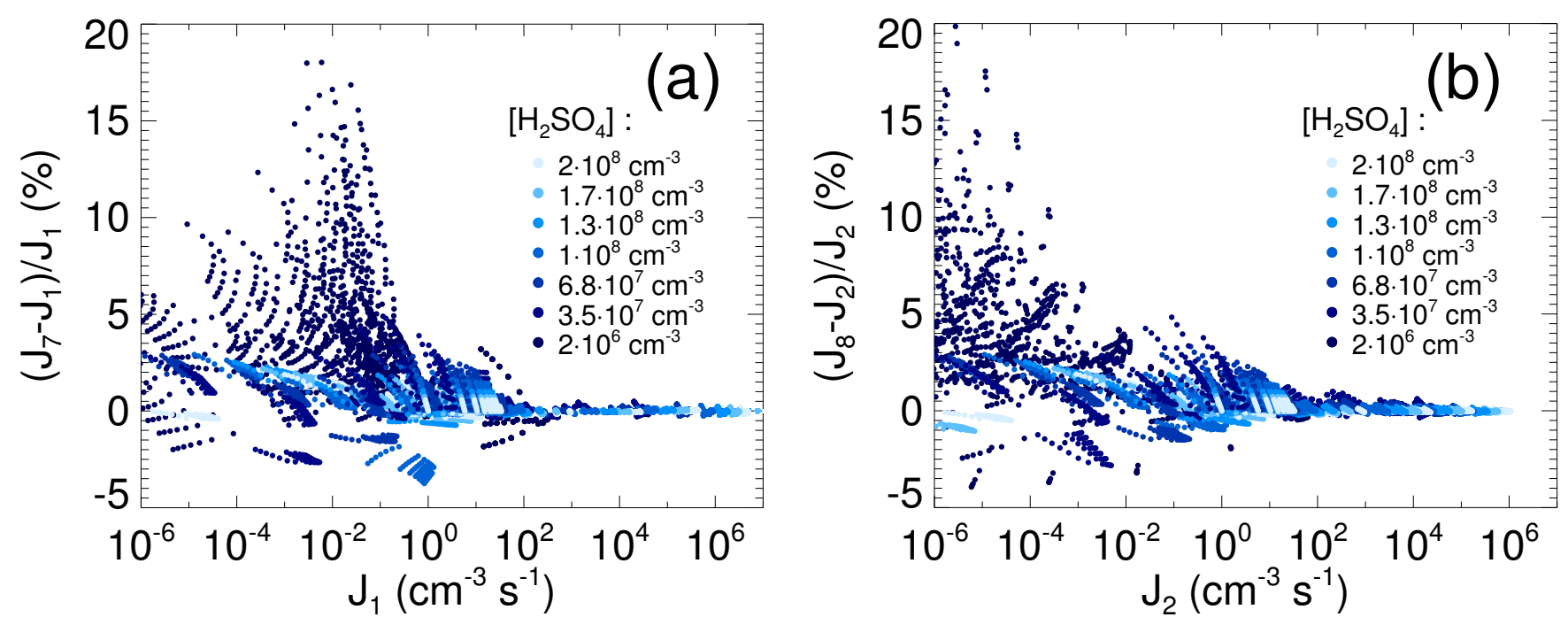

Fig. 7. (a) Comparison of the nucleation rate $J_{7}$, calculated with our semi-analytical method, with the nucleation rate $J_{1}$, calculated with a numerical aerosol model. (b) Comparison of the formation rate $J_{8}$ of aerosol particles exceeding $2.5 \mathrm{~nm}$ in diameter, calculated with our semi-analytical method, with the particle formation rate $J_{2}$, calculated with a numerical aerosol model. The semi-analytical method uses parameterized rate coefficients for the uptake and loss of $\mathrm{H}_{2} \mathrm{SO}_{4}$ by the aerosol particles and parameterized average particle $\mathrm{H}_{2} \mathrm{O}$ contents, while the numerical model calculates the rate coefficients and average particle $\mathrm{H}_{2} \mathrm{O}$ contents from scratch. The particle formation rate calculations are described in more detail in Table 1.

$\mathrm{H}_{2} \mathrm{O}$ contents (Sect. 6), with particle formation rates calculated with the numerical aerosol model described in Sect. 8, which uses $\mathrm{H}_{2} \mathrm{SO}_{4}$ uptake and loss rate coefficients and and average particle $\mathrm{H}_{2} \mathrm{O}$ contents calculated from scratch (Sect. 4). The rate coefficients for coagulation of the particles among each other and with preexisting aerosol are calculated as described in Sect. 4 by both methods.

Figure $7 \mathrm{a}$ shows the relative deviation of the semianalytical nucleation rates with respect to the numerical nucleation rates. The maximum error amounts to $18 \%$. Larger deviations are possible (but do not appear on the used parameter grid) when errors in the parameterized rate coefficients lead to an erroneous determination of the neutral critical cluster $\mathrm{H}_{2} \mathrm{SO}_{4}$ content. Figure $7 \mathrm{~b}$ shows the relative deviation of the semi-analytical formation rates of particles exceeding $2.5 \mathrm{~nm}$ in diameter with respect to the corresponding numerical particle formation rates. Here the maximum error amounts to $20 \%$. In both cases, the deviations are mainly due to errors in the parameterization of the rate coefficients for uptake and loss of $\mathrm{H}_{2} \mathrm{SO}_{4}$ by the aerosol particles.

Figure 8 shows the cumulative error occurrence (fraction of errors exceeding a given value) of the semi-analytical particle formation rates with respect to the numerical particle formation rates. For both the semi-analytical nucleation rate and the $>2.5 \mathrm{~nm}$ particle formation rate the cumulative error occurrence falls off quickly, signifying the rare occurrence of large deviations. The cumulative error occurrences are based on particular samples of particle formation rates, and are therefore subject to a sampling uncertainty.
The semi-analytical method using parameterized rate coefficients and average particle water contents is faster than the numerical model using rate coefficients and average particle water contents calculated from scratch when run for a time period of $1200 \mathrm{~s}$ by a factor of several hundred in the case of the $>2.5 \mathrm{~nm}$ particle formation rates. A further acceleration can be achieved when requirements on precision are relaxed, e.g. by reducing the number of iterations in the semianalytical method, or the maximum order of the Chebyshev polynomial expansion used in the rate coefficient parameterization.

\section{Summary, discussion, and outlook}

Secondary aerosol formation can significantly increase the concentrations of aerosol particles and cloud condensation nuclei in the atmosphere, and therefore requires dependable representations in atmospheric models. However, available representations reproduce aerosol nucleation rates calculated with detailed numerical models only imprecisely. In addition, substantial errors, exceeding an order of magnitude in some cases, can arise when the steady state nucleation rate is used as a surrogate for the steady state formation rate of particles of a given size. To overcome these limitations we have developed a new, semi-analytical method to calculate secondary aerosol formation rates in steady state. The advantages of our method are:

- the use of laboratory thermodynamic parameters for the initial steps of molecular cluster formation from the gas phase, 

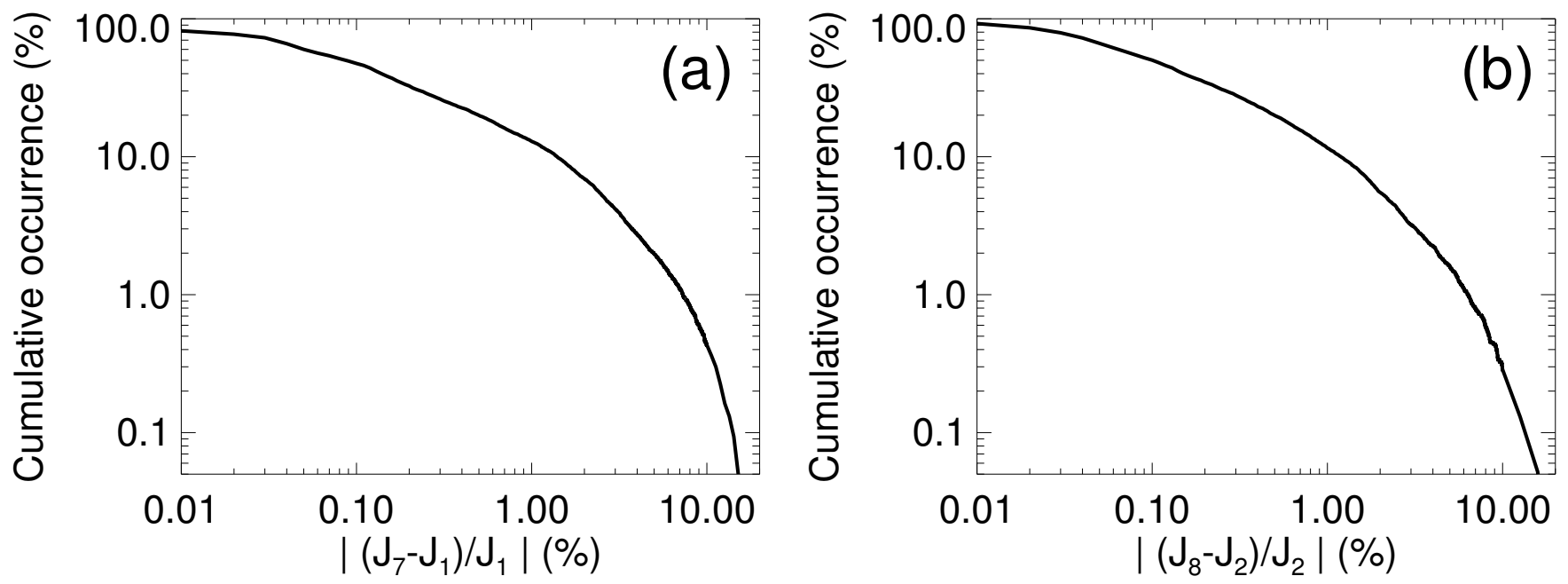

Fig. 8. Cumulative error occurrence (fraction of errors exceeding a given value) of particle formation rates calculated with our semi-analytical method, relative to the particle formation rates calculated with a numerical aerosol model: (a) nucleation rate, (b) formation rate of particles exceeding $2.5 \mathrm{~nm}$ in diameter. See Table 1 for details of the particle formation rate calculations.

- its detailed representation of the physical processes leading to new aerosol formation,

- its ability to calculate nucleation rates as well as the formation rates of particles of a given size,

- the good agreement of the resulting particle formation rates with those calculated by a numerical aerosol model.

Disadvantages of our method include

- its higher complexity compared to aerosol formation rate parameterizations, resulting in a higher numerical cost,

- the limited number of aerosol formation mechanisms accounted for: Potentially important mechanisms such as ternary nucleation of ammonia, sulfuric acid, and water, or nucleation involving organic molecules are not included.

How do we proceed from here with respect to representing aerosol formation from the gas phase in atmospheric modeling? Let us muse about possible developments that may advance the field:

First of all, a procedure for assessing and evaluating the various available and future aerosol formation representations needs to be devised. Simply comparing the output of the different representations is not enough: On the one hand, none of the methods can be considered a standard a priori. On the other hand, the flaws in a given representation may not matter when it is used in an atmospheric model: As an example, the joint probability distribution of the parameters controlling aerosol formation needs not to be uniform in the atmosphere. Then errors of a representation would matter little if they were confined to conditions that occur infrequently, or that contribute little to overall aerosol production. Consequently, assessing and evaluating different implementations should be done using an atmospheric model and comparing its output to observations. In this, it should be noted that large scale models often rely on highly simplified representations of many processes and have a limited spatial resolution. Large scale models may therefore produce good results with a relatively simple but efficient representation of aerosol formation. Smaller scale models, which resolve many processes in detail and on smaller spatial scales may require more sophisticated representations of aerosol formation to produce a good agreement of model results and observations.

The question when steady state representations of aerosol formation are indeed applicable should be addressed: Vigorous nucleation events for example, such as observed in the upper troposphere in connection with tropical convection may not be well captured by steady state methods.

Computer power will continue to grow in the future, and increasingly detailed atmospheric models will become numerically affordable. This situation will require but also enable more complex and detailed representations of secondary aerosol formation. However, before aerosol formation from the gas phase can be represented with a molecular size resolution in large scale atmospheric models, the available methods may have to be further developed. Improvements could be achieved by identifying better sets of basis functions for parameterizing particle formation rates, so that more complex yet precise parameterizations could be constructed with a limited number of terms. In analogy, the method presented in this work would benefit from efficient basis functions for the parameterization of the rate coefficients it uses. It could 
also be accelerated by finding algorithms that reduce the number of iterations required for convergence towards steady state. Another promising approach for representing aerosol formation rates that has not been widely explored yet is the interpolation of lookup tables.

However, the most severe limitation on modeling secondary aerosol formation in the atmosphere is our lack of understanding of the processes that lead to the formation of stable molecular clusters from the gas phase. Laboratory studies investigating the structure of such clusters and measuring their thermodynamic formation parameters have therefore the greatest potential to advance the field.

\section{Conclusions}

Secondary aerosol formation can significantly increase concentrations of aerosol particles and cloud condensation nuclei in the atmosphere, and therefore requires dependable representations in atmospheric models. However, the available representations reproduce aerosol nucleation rates calculated with detailed numerical models only imprecisely. In addition, substantial errors, exceeding an order of magnitude in some cases, can arise when the steady state nucleation rate is used as a surrogate for the steady state formation rate of particles of a given size. To overcome these limitations, we have developed a semi-analytical method to calculate steady state formation rates of sulfate aerosol which uses parameterized rate coefficients for sulfuric acid uptake and loss by the aerosol particles. The method reproduces aerosol formation rates calculated with a numerical aerosol model better than other available methods, but is numerically more complex. The method can calculate the steady state formation rates of particles of a given size, and therefore supersedes the use of nucleation rates in lieu of formation rates of larger particles.

Acknowledgements. We thank S. L. Clegg (University of East Anglia) for providing the computer code for calculating activities of sulfuric acid/water solutions. This work was performed while the first author held a National Research Council Research Associateship Award, and was supported by the NOAA Climate and Global Change Program.

Edited by: M. Kulmala

\section{References}

Allan, J. D., Alfarra, M. R., Bower, K. N., Coe, H., Jayne, J. T., Worsnop, D. R., Aalto, P. P., Kulmala, M., Hyötyläinen, T., Cavalli, F., and Laaksonen, A.: Size and composition measurements of background aerosol and new particle growth in a Finnish forest during QUEST 2 using an Aerodyne Aerosol Mass Spectrometer, Atmos. Chem. Phys., 6, 315-327, 2006, http://www.atmos-chem-phys.net/6/315/2006/.

Bates, D. R.: Recombination of small ions in the troposphere and lower stratosphere, Planet. Space Sci., 30, 1275-1282, 1982.
Brock, C. A., Hamill, P., Wilson, J. C., Jonsson, H. H., and Chan, K. R.: Particle formation in the upper tropical troposphere: a source of nuclei for the stratospheric aerosol, Science, 270, 1650-1653, 1995.

Cavalli, F., Facchini, M. C., Decesari, S., Emblico, L., Mircea, M., Jensen, N. R., and Fuzzi, S.: Size-segregated aerosol chemical composition at a boreal site in southern Finland, during the QUEST project, Atmos. Chem. Phys., 6, 993-1002, 2006, http://www.atmos-chem-phys.net/6/993/2006/.

Clarke, A. D.: Atmospheric nuclei in the remote free-troposphere, J. Atmos. Chem., 14, 479-488, 1992.

Clegg, S. L., Rard, J. A., and Pitzer, K. S.: Thermodynamic properties of $0-6 \mathrm{~mol} \mathrm{~kg}^{-1}$ aqueous sulfuric acid from 273.15 to 328.15 K, J. Chem. Soc., Faraday Trans., 90, 1875-1894, doi: 10.1039/FT9949001875, 1994.

Coffman, D. J. and Hegg, D. A.: A preliminary study of the effect of ammonia on particle nucleation in the marine boundary layer, J. Geophys. Res., 100, 7147-7160, doi:10.1029/94JD03253, 1995.

Curtius, J., Froyd, K. D., and Lovejoy, E. R.: Cluster ion thermal decomposition (I): Experimental kinetics study and ab initio calculations for $\mathrm{HSO}_{4}^{-}\left(\mathrm{H}_{2} \mathrm{SO}_{4}\right)_{(x)}\left(\mathrm{HNO}_{3}\right)_{(y)}$, J. Phys. Chem. A, 105, 10 867-10 873, 2001.

Froyd, K. D.: Ion induced nucleation in the atmosphere: Studies of $\mathrm{NH}_{3}, \mathrm{H}_{2} \mathrm{SO}_{4}$, and $\mathrm{H}_{2} \mathrm{O}$ cluster ions, Ph.D. thesis, Univ. of Colo., Boulder, 2002.

Froyd, K. D. and Lovejoy, E. R.: Experimental Thermodynamics of Cluster Ions Composed of $\mathrm{H}_{2} \mathrm{SO}_{4}$ and $\mathrm{H}_{2} \mathrm{O}$. 1. Positive Ions, J. Phys. Chem. A, 107, 9800-9811, 2003a.

Froyd, K. D. and Lovejoy, E. R.: Experimental Thermodynamics of Cluster Ions Composed of $\mathrm{H}_{2} \mathrm{SO}_{4}$ and $\mathrm{H}_{2} \mathrm{O}$. 2. Measurements and ab Initio Structures of Negative Ions, J. Phys. Chem. A, 107, 9812-9824, 2003b.

Fuchs, N. A.: The Mechanics of Aerosols, Macmillan, 1964.

Giauque, W. F., Hornung, E. W., Kunzler, J. E., and Rubin, T. T.: The thermodynamic properties of aqueous sulfuric acid solutions and hydrates from 15 to $300 \mathrm{~K}$, Am. Chem. Soc. J., 82, 62-70, 1960.

Goff, J. A.: Saturation pressure of water on the new Kelvin temperature scale, in: Transactions of the American Society of Heating and Ventilating Engineers, pp. 347-354, American Society of Heating and Ventilating Engineers, 1957.

Hanson, D. R. and Lovejoy, E. R.: Measurement of the thermodynamics of the hydrated dimer and trimer of sulfuric acid, J. Phys. Chem. A, 110, 9525-9528, doi:10.1021/jp062844w, 2006.

Haywood, J. and Boucher, O.: Estimates of the direct and indirect radiative forcing due to tropospheric aerosols: A review, Rev. Geophys., 38, 513-543, doi:10.1029/1999RG000078, 2000.

Heintzenberg, J.: Fine particles in the global troposphere, Tellus Series B Chemical and Physical Meteorology B, 41, 149-160, 1989.

Heintzenberg, J., Covert, D. S., and Van Dingenen, R.: Size distribution and chemical composition of marine aerosols: A compilation and review, Tellus, 52B, 1104-1122, 2000.

Jacobson, M. C., Hansson, H.-C., Noone, K. J., and Charlson, R. J.: Organic atmospheric aerosols: Review and state of the science, Rev. Geophys., 38, 267-294, doi:10.1029/1998RG000045, 2000.

Kazil, J., Lovejoy, E. R., Jensen, R. J., and Hanson, D. R.: Is aerosol formation in cirrus clouds possible?, Atmos. Chem. Phys., 7, 
2007.

Kerminen, V.-M. and Kulmala, M.: Analytical formulae connecting the "real" and the "apparent" nucleation rate and the nuclei number concentration for atmospheric nucleation events, J. Aerosol Sci., 33, 609-622, doi:10.1016/S0021-8502(01)00194-X, 2002.

Kulmala, M., Vehkamäki, H., Petäjä, T., Dal Maso, M., Lauri, A., Kerminen, V.-M., Birmili, W., and McMurry, P. H.: Formation and growth rates of ultrafine atmospheric particles: A review of observations, J. Aer. Sci., 35, 143-176, doi:10.1016/j.jaerosci. 2003.10.003, 2004a.

Kulmala, M., Kerminen, V.-M., Anttila, T., Laaksonen, A., and O'Dowd, C. D.: Organic aerosol formation via sulphate cluster activation, J. Geophys. Res., 109, D4205, doi:10.1029/ 2003JD003961, 2004b.

Lauer, A., Hendricks, J., Ackermann, I., Schell, B., Hass, H., and Metzger, S.: Simulating aerosol microphysics with the ECHAM/MADE GCM - Part I: Model description and comparison with observations, Atmos. Chem. Phys., 5, 3251-3276, 2005, http://www.atmos-chem-phys.net/5/3251/2005/.

Lehtinen, K. E. J. and Kulmala, M.: A model for particle formation and growth in the atmosphere with molecular resolution in size, Atmos. Chem. Phys., 3, 251-258, 2003, http://www.atmos-chem-phys.net/3/251/2003/.

Lohmann, U. and Feichter, J.: Global indirect aerosol effects: a review, Atmos. Chem. Phys., 5, 715-737, 2005, http://www.atmos-chem-phys.net/5/715/2005/.
Lovejoy, E. R., Curtius, J., and Froyd, K. D.: Atmospheric ioninduced nucleation of sulfuric acid and water, J. Geophys. Res., 109, D08204, doi:10.1029/2003JD004460, 2004.

$\mathrm{Ma}, \mathrm{X}$. and von Salzen, K.: Dynamics of the sulphate aerosol size distribution on a global scale, J. Geophys. Res., 111, D08 206, doi:10.1029/2005JD006620, 2006.

Modgil, M. S., Kumar, S., Tripathi, S. N., and Lovejoy, E. R.: A parameterization of ion-induced nucleation of sulphuric acid and water for atmospheric conditions, J. Geophys. Res., 110, D19205, doi:10.1029/2004JD005475, 2005.

Napari, I., Noppel, M., Vehkamäki, H., and Kulmala, M.: Parametrization of ternary nucleation rates for $\mathrm{H}_{2} \mathrm{SO}_{4}-\mathrm{NH}_{3}-$ $\mathrm{H}_{2} \mathrm{O}$ vapors, J. Geophys. Res., 107, 6-1, doi:10.1029/ 2002JD002132, 2002.

Ravishankara, A. R.: Heterogeneous and Multiphase Chemistry in the Troposphere, Science, 276, 1058-1065, doi:10.1126/science. 276.5315.1058, 1997.

Smith, J. N., Moore, K. F., Eisele, F. L., Voisin, D., Ghimire, A. K., Sakurai, H., and McMurry, P. H.: Chemical composition of atmospheric nanoparticles during nucleation events in Atlanta, J. Geophys. Res., 110, D22S03, doi:10.1029/2005JD005912, 2005.

Vehkamäki, H., Kulmala, M., Napari, I., Lehtinen, K. E. J., Timmreck, C., Noppel, M., and Laaksonen, A.: An improved parameterization for sulfuric acid-water nucleation rates for tropospheric and stratospheric conditions, J. Geophys. Res., 107, 4622, doi: 10.1029/2002JD002184, 2002. 